\title{
Testosterone and the metabolic syndrome
}

\author{
Vakkat Muraleedharan and T. Hugh Jones
}

\begin{abstract}
Metabolic syndrome and testosterone deficiency in men are closely linked. Epidemiological studies have shown that low testosterone levels are associated with obesity, insulin resistance and an adverse lipid profile in men. Conversely in men with metabolic syndrome and type 2 diabetes have a high prevalence of hypogonadism. Metabolic syndrome and low testosterone status are both independently associated with increased all-cause and cardiovascular mortality. Observational and experimental data suggest that physiological replacement of testosterone produces improvement in insulin resistance, obesity, dyslipidaemia and sexual dysfunction along with improved quality of life. However, there are no longterm interventional studies to assess the effect of testosterone replacement on mortality in men with low testosterone levels. This article reviews the observational and interventional clinical data in relation to testosterone and metabolic syndrome.
\end{abstract}

Keywords: diabetes, insulin resistance, metabolic syndrome, obesity, testosterone deficiency

\section{Introduction}

Obesity has reached epidemic proportions globally, with more than 1 billion adults overweight at least 300 million of them clinically obese [WHO, 2010]. It leads to adverse metabolic effects on blood pressure, lipid and glucose metabolism mediated by insulin resistance. This constellation of cardiovascular risk factors, constitute the metabolic syndrome. The metabolic syndrome is associated with significant increase in cardiovascular morbidity and mortality being the most common cause of death in the Western world. Men are at increased risk of developing coronary artery disease earlier in life compared with women. The reason for this bias toward males is still poorly understood.

The metabolic syndrome was first described in 1923 by Kylin, a Swedish physician, as a clinical association between hypertension and gout [Kylin, 1923]. In 1947, it was modified to include upper body adiposity [Vague, 1947], however it was Reaven in 1988 who emphasized the importance of metabolic syndrome [Reaven, 1988]. He described 'Syndrome X' as a constellation of insulin resistance, hyperglycaemia, hypertension, low high-density lipoprotein (HDL) cholesterol (HDL-C) and increased very-low-density lipoprotein (VLDL) and triglyceride (TG) levels. Since then it has evolved as a major risk factor for coronary artery disease.
The metabolic syndrome is a multiplex risk factor that arises from insulin resistance accompanying abnormal adipose deposition and function [Olufadi and Byrne, 2008]. It is a risk factor for coronary heart disease (CHD), as well as diabetes, fatty liver, and several cancers. The clinical manifestations of this syndrome as described above may include hypertension, hyperglycaemia, hypertriglyceridaemia, reduced HDL-C and abdominal obesity.

A new joint statement from a number of professional organizations has identified specific criteria for the clinical diagnosis of the metabolic syndrome. Patients with three of the five criteria (elevated waist circumference, elevated TGs, reduced HDL-C levels, elevated blood pressure and elevated fasting glucose levels) are considered to have the syndrome. The joint statement includes the participation of the International Diabetes Federation (IDF), the National Heart, Lung, and Blood Institute (NHLBI), the World Heart Federation, the International Atherosclerosis Society and the American Heart Association (AHA) [Alberti et al. 2009].

Adipose tissue is metabolically active and produces cytokines, the adipocytokines, that link the various components of metabolic syndrome and their cardiovascular effects. Central
Ther Adv Endocrinol Metab

(2010) 1(5) 207-223

DOI: 10.1177/

2042018810390258

(C) The Author(s), 2010 Reprints and permissions: http://www.sagepub.co.uk/ journalsPermissions.nav

Correspondence to: Professor T. Hugh Jones, BSc, MD, FRCP

Centre for Diabetes and Endocrinology, Barnsley Hospital, Gawber Road, Barnsley S75 2EP, UK and Department of Human Metabolism, University of Sheffield Medical School, Sheffield, UK. hugh.jonesanhs.net Vakkat Muraleedharan, MBBS, MD, MRCP Robert Hague Centre for Diabetes and

Endocrinology, Barnsley Hospital NHS Foundation Trust, Barnsley and Department of Human Metabolism, University of Sheffield Medical School, Sheffield, UK 
obesity, as measured by waist circumference or waist-hip ratio, strongly correlates independently with insulin resistance and cardiovascular disease. Visceral adipocytes are metabolically more active than subcutaneous adipocytes. Visceral fat is a major source of free fatty acids and adipocytokines to the liver which stimulates gluconeogenesis and inhibits hepatic insulin binding.

Although clinically easy to measure, waist measurements do not fully correlate with visceral obesity as it also measures the subcutaneous fat around the abdomen and back. Radiological methods such as CT, MRI and dual-energy X-ray absorptiometry (DEXA) scanning are better techniques which allow a greater distinction between the two fat deposits but are not yet widely used in clinical practice.

\section{Role of testosterone in the metabolic syndrome}

There is convincing evidence that low testosterone is an independent risk factor for development of metabolic syndrome and type 2 diabetes in men. Furthermore evidence is also accumulating that testosterone deficiency is a cardiovascular risk factor [Jones, 2010]. There are many recent reviews highlighting the important link between hypogonadism, metabolic syndrome, diabetes and cardiovascular disease [Grossmann et al. 2010; Jones, 2010; Corona et al. 2009; DiazArjonilla et al. 2009; Jones and Saad, 2009; Stanworth and Jones, 2009; Traish et al. 2009; Zitzmann, 2009; Shabsigh et al. 2008; Yassin et al. 2008; Makhsida et al. 2005].

There is a strong inverse correlation between body fat and testosterone levels in men [Kapoor et al. 2005]. In men, abdominal obesity has usually been associated with low testosterone levels in cross-sectional [Pasquali et al. 1991; Zumoff et al. 1990] and longitudinal studies [Gapstur et al. 2002; Khaw and Barrett-Connor, 1992]. Waist circumference or waist-hip ratio are also inversely associated with sex hormone-binding globulin (SHBG) levels [Gapstur et al. 2002; Khaw and Barrett-Connor, 1992]. Studies which have measured abdominal fat deposits using imaging techniques such as CT or MRI have confirmed that low testosterone concentrations correlate with greater visceral fat accumulation [Tsai et al. 2004; Garaulet et al. 2000; Haffner et al. 1993; Seidell et al. 1990]. Central fat deposits have a high aromatase activity thus converting more testosterone to oestrogen locally [Vermeulen et al. 2002]. This partially explains the higher level of oestrogens found in obese healthy men. Testosterone also promotes myocyte and inhibits adipocyte development from pluripotent stem cells, thus increasing muscle mass, whereas a state of testosterone deficiency enhances greater fat mass [Singh et al. 2003]. In addition testosterone increases the number of beta-adrenergic receptors which, in turn, promotes lipolysis and reduces fatty acid synthesis [De Pergola, 2000]. Evidence from androgen receptor (AR) knockout mouse models demonstrates that deficiency of androgen action decreases lipolysis and is mainly responsible for the induction of obesity [Yanase et al. 2008].

The hypogonadal-obesity cycle hypothesis was originally put forward by Cohen in 1999 [Cohen, 1999]. Testosterone inhibits adipocytes lipoprotein lipase activity, the enzyme which breaks down circulating TG to absorbable free fatty acids which are taken up into the fat cells and converted back to TG for storage. The hypothesis suggests that low testosterone as a result of high aromatase activity leads to a cycle which promotes increasing adipocyte number and fat deposition which gradually leads to a lower testosterone levels. The hypogonadal-obesity-adipocytokine hypothesis explains why the body cannot respond to low testosterone levels by a compensatory production of the hormone. Oestradiol and the adipocytokines tumour necrosis factor $\alpha(\mathrm{TNF} \alpha)$, interleukin-6 (IL6) and leptin (human obesity is associated with leptin resistance) are all known to inhibit the hypothalamic-pituitary-testicular axis and hence causing a state of hypogonadotrophic hypogonadism (Figure 1) [Jones, 2007]. Also the excess aromatase activity exhibited by obese men results in the suppression of gonadotrophin-mediated testosterone secretion. This is because the bulk of negative feedback exerted by circulating testosterone on the hypothalamo-pituitary axis is actually mediated via its aromatization (either in peripheral adipose tissue or centrally) to oestradiol [Hayes et al. 2001, 2000]. This supports the known association of type 2 diabetes and metabolic syndrome with low gonadotrophins [Dhindsa et al. 2004] and various reports of enhanced luteinizing hormone (LH), follicle-stimulating hormone (FSH) and testosterone secretion in (generally obese) men with aromatase inhibitors and selective oestrogen receptor modulators [Hill et al. 2009]. 


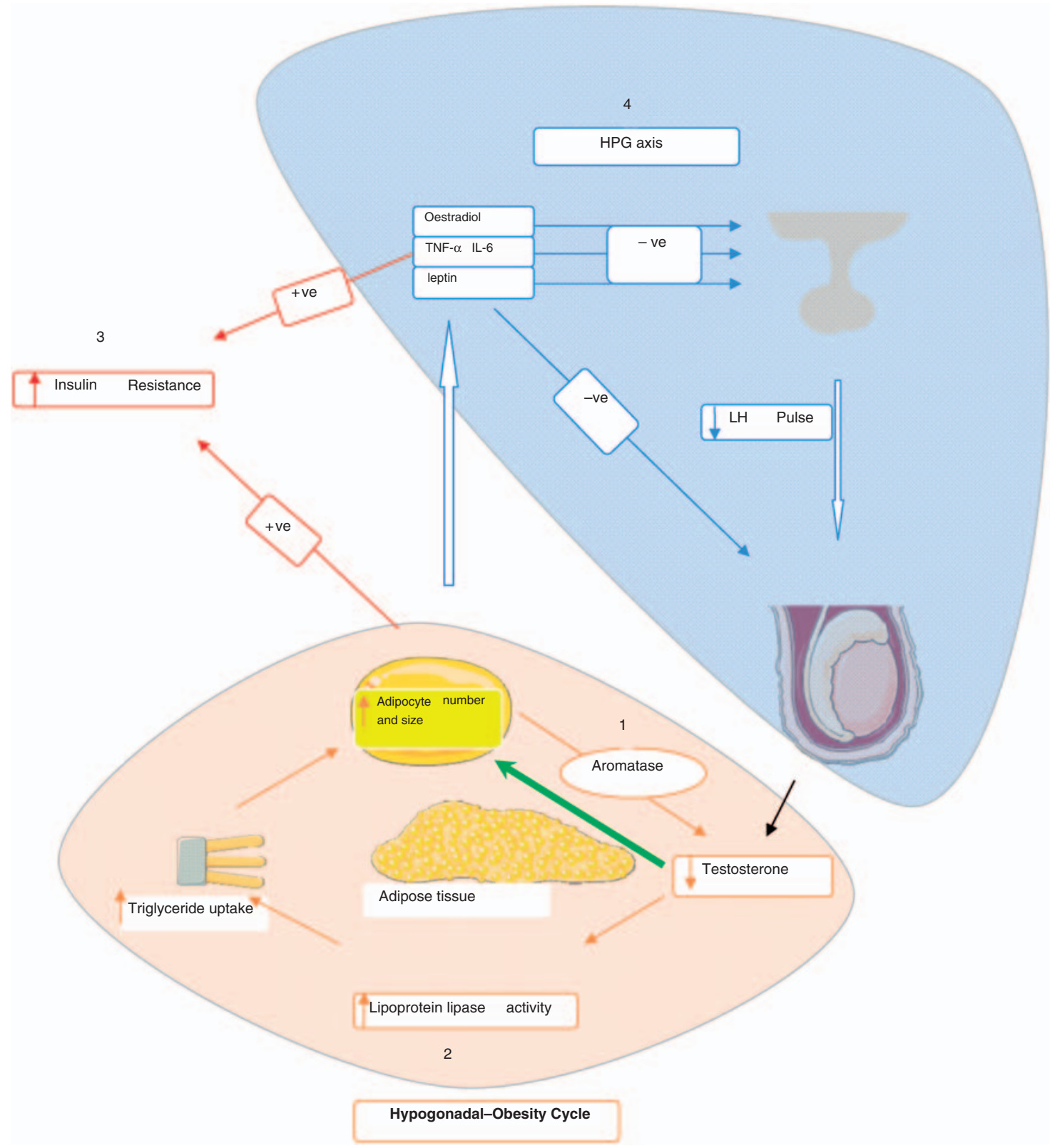

Figure 1. The Hypogonadal-obesity-adipocytokine hypothesis. (1) High aromatase activity in adipocytes converts testosterone to oestradiol. Reduced tissue testosterone facilitates triglyceride storage in adipocytes allowing (2) increased lipoprotein lipase activity and stimulating pluripotent stem cells into mature adipocytes. (3) Increased adipocyte mass is associated with greater insulin resistance. (4) Oestradiol and adipocytokines TNF $\alpha$, IL6 and leptin inhibits the hypothalamic-pituitary-gonadal axis (HPG axis shown in blue shade) response to decreasing androgen levels (blue arrows). Orange shade represents the hypogonadal-obesity cycle. Green arrow, low testosterone promotes the formation of adipocytes from pluripotent stem cells. +ve, positive effect; -ve, negative effect [Jones, 2010]. Some figures were produced using Servier Medical Art- www.servier.com

Testosterone, insulin resistance and diabetes Insulin resistance and hyperglycaemia are the key characteristics of type 2 diabetes which are often associated with obesity. There is now evidence that low testosterone is closely linked to diabetes and testosterone replacement therapy (TRT) can improve insulin sensitivity and glycaemic control.

In a study of 1292 healthy nondiabetic men there was an inverse correlation between total testosterone and insulin levels independent of age and 
obesity [Simon et al. 1992]. In the San Antonio Heart Study the researchers found an inverse relation between total and free testosterone with insulin levels [Haffner et al. 1994]. A metaanalysis of 21 clinical reports which included data from 3825 men confirms that there is a high prevalence of low testosterone levels in men with diabetes and/or metabolic syndrome [Ding et al. 2006]. Conversely men with higher testosterone levels had a $42 \%$ lower risk of type 2 diabetes. There are also studies which suggest that low testosterone may in fact be a precursor of development of diabetes or insulin resistance [Kupelian et al. 2006; Laaksonen et al. 2004; Oh et al. 2002; Stellato et al. 2000; Haffner et al. 1996]. The third National Health and Nutrition Survey (NHANESIII) found that men in the lowest tertile of free or bioavailable (free + albumen bound - the biologically active fraction) testosterone are more likely to have diabetes when compared with the upper tertile after adjustment for age and obesity [Selvin et al. 2007].

Kapoor and colleagues demonstrated in a recent cross-sectional study of 355 men with type 2 diabetes, that overt hypogonadism (defined as the presence of clinical symptoms of hypogonadism and total testosterone $<8 \mathrm{nmol} / 1$ and/or bioavailable testosterone $<2.5 \mathrm{nmol} / \mathrm{l}$ ) was present in $17 \%$ of individuals. Borderline hypogonadism was found in a further $25 \%$ of individuals [Kapoor et al. 2007a]. Another study investigated the prevalence of hypogonadism in type 2 diabetes by measuring free testosterone by equilibrium dialysis in a cohort of 103 type 2 diabetes patients [Dhindsa et al. 2004]. They found that $33 \%$ of these men had free testosterone below the normal range consistent with biochemical hypogonadism.

Several longitudinal studies have shown that low testosterone is an independent risk factor for the development of diabetes and metabolic syndrome. Baseline testosterone levels correlate inversely with the accumulation of central fat but not other fat deposits in a cohort of 110 men [Tsai et al. 2000]. Three other studies, the Massachusetts Male Aging Study (MMAS) [Stellato et al. 2000], the Multiple Risk Factor Intervention Trial (MRFIT) [Haffner et al. 1996] and Rancho Bernado [Oh et al. 2002], showed an inverse correlation between baseline testosterone and the future development of diabetes. A Finnish study showed that low baseline testosterone and SHBG predicted metabolic syndrome and diabetes after a 11-year follow up [Laaksonen et al. 2004].

The mechanisms linking testosterone with insulin resistance and type 2 diabetes are still not fully understood. Although testosterone deficiency leads to increased fat deposition and this would result in increasing insulin resistance, it may not explain the total action on insulin sensitivity. For example, one study which assessed insulin resistance by hyperinsulinaemic/euglycaemic clamps in 60 men with a range of glucose tolerance from normal to diabetic levels [Pitteloud et al. 2005]. Their findings confirmed an inverse relation between total testosterone and insulin resistance. From muscle biopsies they showed that low testosterone impairs mitochondrial oxidative phosphorylation. As up to $70 \%$ of the body's insulin sensitivity can be accounted for by muscle this tissue may develop reduced insulin sensitivity in the hypogonadal state sufficient to contribute in part to the overall state of insulin resistance.

\section{Testosterone and metabolic syndrome}

Low testosterone as explained above is closely linked to the metabolic syndrome. Hypogonadal men exhibit an increased body fat mass. For example, in a study of 57 men aged between 70 and 80 years, testosterone levels were negatively correlated with percentage body fat [Vermeulen et al. 1999]. There are a number of epidemiological studies linking testosterone and metabolic syndrome. One of them is a Finnish study of 1896 nondiabetic men where they found free and total testosterone levels were significantly lower in those with metabolic syndrome [Laaksonen et al. 2003]. Similarly the Quebec Family study found higher levels of testosterone reduced the risk of metabolic syndrome and increased insulin sensitivity [Blouin et al. 2005]. Conversely a study of 803 men showed that hypogonadism is common in those with metabolic syndrome [Corona et al. 2006].

The data from the Baltimore Longitudinal Study of Aging looking at 618 community-dwelling healthy adult men with a mean age of 63 years reported that age alone did not predict the development of the metabolic syndrome. Total testosterone and SHBG were inversely related to the development of the metabolic syndrome over a mean follow-up period of 5.8 years and the free 
testosterone index and body mass index were positively related to the incidence of the metabolic syndrome [Rodriguez et al. 2007]. Another important report analysing 950 men without metabolic syndrome from the Massachusetts Male Aging Study has demonstrated that low testosterone levels in a nonobese population were found to predict the later onset of the metabolic syndrome [Kupelian et al. 2006].

Data from the Finnish study noted above also reported that men with metabolic syndrome at baseline are at an increased risk of developing hypogonadism based on an 11-year follow up [Laaksonen et al. 2005]. A recent cross-sectional study from Australia involving 2502 communitydwelling men aged $\geq 70$ years without known diabetes reported that men with hypogonadotrophic hypogonadism have a high prevalence of metabolic syndrome [Chubb et al. 2008].

\section{Dyslipidaemia and hypertension}

HDL-C and TG levels comprise two central components of the metabolic syndrome whereas total and low-density lipoprotein (LDL) cholesterol (LDL-C) are not. Raised total cholesterol, LDL-C and TG confer risk for future cardiovascular events whilst HDL-C is protective against atherosclerosis and low levels are associated with increased cardiovascular risk. HDL-C presents a complicated picture and the effect seems to be gender specific [Fan and Dwyer, 2007]. Low HDL correlates with CHD more in men than women [Johnsen et al. 2005]. In both healthy and diabetic men, testosterone correlates positively with HDL level [Stanworth et al. 2007; Van Pottelbergh et al. 2003].

In the context of cardiovascular disease and the fact that elevated total cholesterol and LDL-C is common in type 2 diabetes, the management of this hyperlipidaemia in type 2 diabetes is vital for the prevention of cardiovascular events.

Derangements in lipid metabolism play a pivotal role in the formation of atherosclerotic plaque. High total cholesterol and LDL-C are proatherogenic where as high HDL seems to be protective against atherosclerosis [Maron, 2000; Simons et al. 1998]. The same pathogenic process is also implicated in the development of metabolic syndrome and type 2 diabetes although elevated total cholesterol and LDL-C are not part of the definition of the metabolic syndrome.
Declining levels of testosterone with age is associated with a relative increase in oestrogen levels through the increased aromatase activity [Cohen, 2008, 2001]. The increased oestrogen levels are associated with increased circulating cholesterol and more atherogenic lipoprotein particles [Tomaszewski et al. 2009; Vaidya et al. 2008; Yasui et al. 2008].

A number of studies have shown a negative correlation between testosterone levels and total cholesterol and LDL-C [Simon et al. 1997; Haffner et al. 1993; Barrettconnor, 1992]. A meta-analysis of 19 clinical trials in hypogonadal men reports that significant reductions in total cholesterol and LDL-C is associated with intramuscular TRT [Whitsel et al. 2001].

Studies have shown that low testosterone levels are associated with known hypertension [Bocchi et al. 2008; Kapoor et al. 2007b; Svartberg et al. 2004; Khaw and Barrettconnor, 1988; Messerli et al. 1987]. Conversely men with anabolic steroid abuse are known to have an increased risk of developing hypertension [Maravelias et al. 2005; Mottram and George, 2000; Sullivan et al. 1998].

\section{Effect of androgen suppression on obesity and diabetes}

There are studies from special groups of patients where hypogonadism is a feature, either due to genetic defects or due to pharmacotherapy, which strengthens opinion that testosterone deficiency is a risk factor for the development of the metabolic syndrome and type 2 diabetes, and is an independent cardiovascular risk factor.

A longitudinal study followed a large population of 73,196 men with loco-regional prostate cancer followed for a median of 4.55 years (mean age of 74.2years at diagnosis) [Keating et al. 2006]. Those treated with androgen suppression therapy were more likely to have a higher hazard ratio of developing diabetes, ischaemic heart disease, myocardial infarction and sudden death from cardiovascular disease compared with those patients untreated or treated with other modalities. Similarly a study of 396 men with prostate cancer undergoing androgen-deprivation therapy showed worsening glycaemic control with an increase in $\mathrm{HbAlc}$ and an increased incidence of new onset of diabetes [Derweesh et al. 2007]. A smaller study showed that initiation of $\mathrm{GnRH}$ agonist or anti-androgen therapy in 22 men with 
prostate cancer led to increases in serum insulin, arterial stiffness and fat mass over the subsequent 3-month period [Smith et al. 2001].

Men with Klinefelter's syndrome, the most common classical form of hypogonadism, have an increased risk of death from diabetes, cancer, cardiovascular and respiratory diseases [Bojesen et al. 2006]. This again supports an association of testosterone deficiency states with these major causes of mortality.

Acute withdrawal of testosterone replacement from men with idiopathic hypogonadotropic hypogonadism caused significant rises in fasting insulin, HOMA-IR (Homeostatic Model Assessment Insulin Resistance), IL6 and TNF $\alpha$. This occurred after just 2 weeks of suspension of treatment [Yialamas et al. 2007].

\section{Testosterone and atherosclerosis}

Several studies have demonstrated that low testosterone is associated with the presence of atherosclerosis [Jones and Saad, 2009]. The degree of atherosclerosis in the carotid artery as assessed by intimal media thickness (IMT) and plaque scores is correlated with low testosterone [Svartberg et al. 2006; Demirbag et al. 2005; Muller et al. 2004; Fukui et al. 2003]. A 4-year follow-up study demonstrated that low testosterone led to increased deterioration of the IMT [Muller et al. 2004]. This provides evidence to support the hypothesis that testosterone deficiency promotes the pathogenesis of atherosclerosis. Low testosterone also correlates with the degree of aortic atherosclerosis [Hak et al. 2002].

The major modifiable cardiovascular risk factors are smoking, hypertension, elevated LDL-C, diet, lack of exercise, abdominal obesity and diabetes [Yusuf et al. 2004]. Whilst not constituting a formal diagnostic criterion for the metabolic syndrome, the condition and type 2 diabetes are both recognized to be pro-inflammatory states, with a number of cytokines and adipokines being proposed to be involved in the pathophysiology of insulin resistance. Furthermore, pro-inflammatory cytokines are also intimately involved in the atherosclerotic process, and both type 2 diabetes and the metabolic syndrome are strong risk factors for, and often coexist with, CHD. Evidence suggests that pro-inflammatory cytokines play crucial role in the development of atherosclerosis [Jones and Saad, 2009]. In vitro studies suggest that testosterone has immunomodulatory properties [Jones and
Saad, 2009]. Testosterone has been shown to suppress the expression of IL6, IL1 $\beta$ and TNF $\alpha$ in human cell lines [Hatakeyama et al. 2002; D'Agostino et al. 1999; Gornstein et al. 1999; Hofbauer et al. 1999; Li et al. 1993] and stimulating production of anti-inflammatory IL10 [Liva and Voskuhl, 2001]. In a detailed study of the relation between testosterone and inflammatory cytokines in men with low testosterone and stable coronary artery disease, serum IL $1 \beta$ inversely correlated with testosterone [Nettleship et al. 2007b; Malkin et al. 2004a]. In men with type 2 diabetes highly sensitive C-reactive protein (CRP) and IL6 also are inversely correlated with testosterone [Kapoor et al. 2007c].

Adiponectin is well known to have an atheroprotective action. In two studies, one with hypogonadal men and the second with hypogonadal men with type 2 diabetes, both found that testosterone replacement reduced serum adiponectin. There is no clear explanation for this but may be proportional to reduction in fat cell mass and further investigation is needed [Kapoor et al. 2007c; Lanfranco et al. 2004].

Animal models have demonstrated that androgen-deficient states including orchidectomy or lack of an active androgen receptor develop lipid streak formation on high cholesterol diets whereas testosterone replete littermate controls do not [Nettleship et al. 2007a; Alexandersen et al. 1999].

\section{Role of the androgen receptor in diabetes, obesity and metabolic syndrome}

The biological function of testosterone (androgenisity) is a function both of testosterone level and of the efficiency of transcriptional activity mediated by the interaction of testosterone with the androgen receptor. Serum total (or even free) testosterone level is only a surrogate marker for the functions testosterone. The androgen receptor (AR) gene contains a polymorphic CAG repeat sequence in exon 1 which encodes a variable length polyglutamine stretch AR CAG. The length of this sequence correlates with the transcriptional activity of AR with longer AR CAG sequences associated with reduced transcriptional activity. Longer AR CAG was associated with increased body fat and leptin levels in a study of 106 healthy men [Zitzmann and Nieschlag, 2003] and in a study of 233 men with type 2 diabetes [Stanworth et al. 2008]. The latter study demonstrated that increased 
central adiposity as measured by waist circumference was greater in association with a less sensitive AR. Longer AR CAG sequences are also associated with higher serum insulin levels in healthy men [Zitzmann and Nieschlag, 2003] but did not correlate with HbAlc in diabetic men [Stanworth et al. 2008].

Men with Kennedy's syndrome, which is a neurological disease caused by abnormally long AR CAG (CAG > 37 repeats), are reported to be more likely to develop diabetes. This might suggest that AR CAG may have a potential role in the pathogenesis of diabetes in this context; however, the distribution of CAG repeat numbers in diabetic men is similar to a healthy population.

AR CAG length also correlates positively with HDL-C levels in diabetic men [Zitzmann et al. 2001]. As mentioned previously serum testosterone also positively correlates with HDL-C. This implies that the effect of testosterone on HDL-C may be mediated independently of the AR. Animal work suggests that this action of testosterone may be mediated by its conversion to oestradiol [Nettleship et al. 2007a].

\section{Testosterone and mortality}

The metabolic syndrome is associated with a significant increase in morbidity and mortality. This is mainly attributed to cardiovascular disease but there is also increased mortality due to cancer [Hanefeld et al. 2007; Zitzmann and Nieschlag, 2003]. Over the last 3 years there have been many epidemiological studies [Laughlin et al. 2008; Khaw et al. 2007; Shores et al. 2006] which have demonstrated that low testosterone status is associated with increased mortality. Most of these studies have reported an increase in all-cause and cardiovascular mortality. On the other hand, there are at least two major studies which showed a weak association or no significant association between testosterone levels and mortality [Araujo et al. 2007; Smith et al. 2005b]. Results of major epidemiological studies are shown in Table 1 .

A 7-year follow-up study of 930 men with CHD proven by angiography has shown that a low testosterone is a major risk factor for all-cause (hazard ratio [HR] 2.25) and cardiovascular mortality only surpassed by reduced left-ventricular function at baseline for all-cause mortality (HR 3.85) [Malkin et al. 2010]. More recently, in a 6-year follow-up study involving 587 men with type 2 diabetes from Barnsley, United Kingdom, the researchers found that low baseline testosterone levels were also associated with increased all-cause and cardiovascular mortality [Muraleedharan et al. 2010].

\section{Effect of testosterone replacement on components of metabolic syndrome}

One of the earliest studies reporting effect of TRT on obesity was by Rebuffescrive and coworkers in 1991. In a small group of 11 men it was found that waist-hip ratio decreased in 9 out of 11 men after 6 weeks of testosterone replacement. This finding has been confirmed in subsequent larger studies [Rebuffescrive et al. 1991]. Recently, however, there have been a number of studies published investigating the effect of testosterone replacement in men primarily in men with type 2 diabetes and with metabolic syndrome.

Boyanov and colleagues reported a study of 48 type 2 diabetic men with symptoms of androgen deficiency [Boyanov et al. 2003]. It was an open-label, randomized, nontreatment, (nonplacebo-)controlled study undertaken over 3 months. Patients received $120 \mathrm{mg}$ oral testosterone undecanoate daily, in divided doses of $80 \mathrm{mg}$ at breakfast and $40 \mathrm{mg}$ at the evening meal $(n=24)$ or no treatment $(n=24)$. Compared with the nontreatment group, testosterone treatment resulted in significant reductions in weight, waist-hip ratio and percentage body fat. Fasting blood glucose (FBG) and postprandial blood glucose levels were reduced significantly, and HbAlc fell by $1.8 \% \quad(p<0.05)$. No significant effects on lipid parameters were observed. The limitations of this study are that there was no placebo group and that more intensive clinic visits itself might have had a beneficial effect on glycaemic control. However, this study provided the first evidence that testosterone treatment may offer clinical benefit to men with type 2 diabetes.

The first double-blind placebo-controlled study was published by Kapoor and colleagues which enrolled 24 patients with type 2 diabetes with a clinical diagnosis of hypogonadism [Kapoor et al. 2007c]. This study was a double-blind placebocontrolled crossover design, with patients randomized to treatment with either testosterone first or placebo first by a computer-generated system; each treatment phase was of 3 months 
Table 1. Major epidemiological studies on testosterone levels and mortality in men.

\begin{tabular}{|c|c|c|c|c|c|}
\hline Study & Population & $N$ & $\begin{array}{l}\text { Follow up } \\
\text { (years) }\end{array}$ & $\begin{array}{l}\text { Age group } \\
\text { (years) }\end{array}$ & Major outcome \\
\hline $\begin{array}{l}\text { Laughlin et al. [2008] } \\
\text { (Rancho Bernado) }\end{array}$ & Community dwelling & 794 & 11.8 & $50-91$ & $\begin{array}{l}\text { Low TT } \mathbf{A} \text { all-cause } \\
\text { (HR 1.88) CV (HR 1.38) } \\
\text { and respiratory (HR 2.29) }\end{array}$ \\
\hline $\begin{array}{l}\text { Shores et al. [2006] } \\
\text { (Veterans) }\end{array}$ & $\begin{array}{l}\text { Male veterans, } \\
\text { hospital based }\end{array}$ & 858 & 4.3 & $>40$ & $\begin{array}{l}\text { Low TT } \boldsymbol{\uparrow} \text { all-cause } \\
\text { mortality (HR 1.88) }\end{array}$ \\
\hline $\begin{array}{l}\text { Khaw et al. [2007] } \\
\text { (EPIC-Norfolk) }\end{array}$ & $\begin{array}{l}\text { Community, nested } \\
\text { case-control }\end{array}$ & 11,600 & 7 & 40-79 & $\begin{array}{l}\text { Low TT } \boldsymbol{A} \text { all-cause mortality } \\
\text { (OR 0.59), CV (OR 0.62) } \\
\text { and cancer (0.59) }\end{array}$ \\
\hline Haring et al. [2010] (Pomerania) & Community dwelling & 1954 & 7.2 & $20-79$ & $\begin{array}{l}\text { Low TT } \boldsymbol{\uparrow} \text { all-cause mortality } \\
\text { (HR 2.32), CV (2.56) } \\
\text { and cancer (HR 3.46) }\end{array}$ \\
\hline Vikan et al. [2009] (Tromso) & Community dwelling & 1568 & 10 & $59 \pm 10.2$ & $\begin{array}{l}\text { Low free TT } \boldsymbol{\uparrow} \text { all-cause } \\
\text { morality Vikan et al. } \\
\text { [2009] (HR 1.24) }\end{array}$ \\
\hline Tivesten et al. [2009] (Swedish MrOS) & Community dwelling & 3014 & 4.5 & $69-80$ & $\begin{array}{l}\text { Low TT } \boldsymbol{\uparrow} \text { all-cause mortality } \\
\text { (HR 1.65) }\end{array}$ \\
\hline Smith et al. [2005b] (Caerphily) & Community dwelling & 2512 & 16.5 & $45-59$ & $\begin{array}{l}\text { Low TT } \leftrightarrow \text { all-cause and } \\
\text { CV mortality }\end{array}$ \\
\hline Araujo et al. [2007] (MMAS) & Community dwelling & 1709 & 15.3 & 40-70 & $\begin{array}{l}\text { Low TT } \leftrightarrow \text { all-cause and } \\
\text { CV mortality }\end{array}$ \\
\hline
\end{tabular}

duration separated by a 1-month washout period. Testosterone treatment was with $200 \mathrm{mg}$ testosterone esters administered as a deep intramuscular injection once every 2 weeks. The final assessment of clinical parameters was made 12-14 days after the final injection. Testosterone treatment resulted in a significant improvement in the HOMA-IR index in those patients not receiving insulin therapy $(n=14)$ and resulted in a reduction in insulin dose by an average of 7 units per day in those patients on insulin therapy $(n=10)$. In the entire patient population statistically significant reductions in both FBG $(-1.58 \mathrm{mmol} / \mathrm{l})$ and fasting insulin were observed, with $\mathrm{HbA} 1 \mathrm{c}$ falling by $0.4 \%$ $(p=0.03)$. In addition to improvement in blood glucose parameters, testosterone treatment also resulted in statistically significant improvement in waist circumference, waist-hip ratio and total cholesterol $(-0.4 \mathrm{mmol} / \mathrm{l})$ although no significant effect was observed on HDL-C, LDL-C, TGs or blood pressure

Another important study is by Heufelder and colleagues investigating the effects of TRT in men with type 2 diabetes [Heufelder et al. 2009]. This was undertaken over a 52-week treatment period, and therefore representing the first longer-term investigation. The study enrolled 32 hypogonadal men with newly diagnosed, treatment-naïve type 2 diabetes but with the added criteria of also having metabolic syndrome. All patients were also abdominally obese in addition to having hypogonadism and type 2 diabetes. The study was a single-blind, randomized design and was not placebo controlled, with patients either receiving diet and exercise advice alone, or diet and exercise advice in conjunction with $50 \mathrm{mg}$ testosterone gel once daily. Compared with diet and exercise 
alone, testosterone treatment resulted in a statistically significant improvement in $\mathrm{HbAlc}$ of $-0.8 \% \quad(p<0.001)$, with all patients attaining an $\mathrm{HbAlc}$ of $<7.0 \%$ and $87.5 \%$ of patients attaining an $\mathrm{HbA} 1 \mathrm{c}<6.5 \%$ markedly more than in the diet and exercise alone arm. This was combined with a statistically significant reduction in the HOMA-IR index, although the observed treatment-mediated reduction in FPG $(-0.3 \mathrm{mmol} / \mathrm{l})$ narrowly failed to achieve statistical significance $(p=0.06)$. In addition, a significant improvement in waist circumference was observed. Testosterone treatment was also associated with a statistically significant reduction in serum levels of TGs and a statistically significant increase in serum levels of HDL-C.

A large multicentre, randomized, double-blind, placebo-controlled study was recently undertaken in eight European countries, providing suitable statistical power to test this hypothesis formally (currently only published in abstract form) [Jones et al. 2010]. The TIMES2 (Testosterone replacement In men with Metabolic Syndrome or type 2 diabetes) study recruited 220 hypogonadal men (aged $\geq 40$ years) diagnosed with either type 2 diabetes and/or the metabolic syndrome (defined according to the IDF criteria) with either a total serum testosterone $<11 \mathrm{nmol} / 1$ or calculated free serum testosterone $<255 \mathrm{pmol} / \mathrm{l}$, and/or at least two symptoms of hypogonadism with no TRT within the previous 6 months. Patients were stratified according to disease status (type 2 diabetes and/or metabolic syndrome) and were randomized to receive TRT initially as a $60 \mathrm{mg}$ /day transdermal gel, which was subsequently dose adjusted to $20-80 \mathrm{mg} /$ day to achieve serum testosterone levels $>17 \mathrm{nmol} / \mathrm{l}$ with dummy dose adjustment in the placebo group. Insulin resistance as assessed by HOMA-IR improved after 6 and 12 months of therapy. TRT was also associated improvement in the sexual function, reductions in percentage of body fat, total cholesterol and LDL-C and lipoprotein a after 6 months but no significant effects on HDL-C or TGs. HbAlc was $0.58 \%$ lower compared with placebo after 9 months treatment but no differences prior to this timepoint.

Other studies have similarly demonstrated an improvement in waist circumference [Saad et al. 2008, 2007] and fat mass [Agledahl et al. 2008; Kenny et al. 2001] with testosterone replacement. One of the links between visceral adiposity and type 2 diabetes is thought to occur through the exposure of the liver to free fatty acids derived from central adipocytes. Testosterone decreases visceral fat mass which reduces the waist circumference. It also reduces insulin resistance by decreasing the exposure of free fatty acids to the liver. It is also noted that testosterone reduces lipoprotein lipase activity a key enzyme involved in the uptake of TGs into adipocytes. [Marin et al. 1995; Rebuffescrive et al. 1991].

Physiological replacement of testosterone has been shown to decrease total cholesterol and LDL-C [Muraleedharan, 2010; Fan and Dwyer, 2007; Malkin et al. 2004a, 2004b]. Studies on the effect of testosterone replacement on HDL-C have yielded differing and confounding results with either a decrease [Bagatell et al. 1994; Thompson et al. 1989], no change [Kapoor et al. 2006; Malkin et al. 2004b; Uyanik et al. 1997; Zgliczynski et al. 1996] or some reporting an increase in the HDL concentration [Saad et al. 2007; Zitzmann and Nieschlag, 2007]. It has been postulated that testosterone increases the shuttling of cholesterol back to the liver from peripheral tissues resulting in an initial lowering of HDL-C before stabilization of levels. Higher testosterone and/or oestradiol levels may increase HDL-C over a longer duration as is the case in statin therapy. Apart from one published study in elderly men [Saad et al. 2008] with late-onset hypogonadism where testosterone replacement reduced TGs, other studies have found no change.

Animal studies have shown that in young orchidectomized hypertensive rats, testosterone replacement exacerbates systolic hypertension [Reckelhoff et al. 1998]. Testosterone increases tubular sodium and water reabsorption [Reckelhoff et al. 2005]. One clinical study showed testosterone replacement in men with hypopituitarism increases extracellular water and decreases aldosterone levels, but the plasma rennin and atrial natriuretic peptide levels are unaffected. Systolic and diastolic blood pressures remained unchanged in this study [Johannsson et al. 2005]. Physiological replacement might have a beneficial effect on blood pressure. There are reports of significant reduction in diastolic and systolic blood pressure [Zitzmann and Nieschlag, 2007; Anderson et al. 1996; Marin et al. 1993] after TRT. Marin and colleagues were the first to report a significant reduction in diastolic blood pressure after TRT 
in obese middle-aged men, along with a reduction in visceral fat, FBG, TGs and total cholesterol. Zitzmann and colleagues in a study of 66 hypogonadal men (mean age $38 \pm 9.9$ years), reported that testosterone substitution resulted in a significant decrease in serum levels of LDL-C, resting diastolic and systolic blood pressure and heart rate. Another important study by Anderson and colleagues (Anderson et al. 1996) in men with osteoporosis intramuscular testosterone for 6 months showed significant reduction in diastolic blood pressure along with total cholesterol, TGs and HDL-C.

Several clinical studies have reported that TRT in hypogonadal individuals results in a reduction in the ex vivo production [Corrales et al. 2006] or the circulating concentration [Agarwal and Oefelein, 2005; Malkin et al. 2004a, 2004b] of a number of pro-inflammatory cytokines. A study of hypogonadal men where the majority of subjects had CHD demonstrated that TRT suppressed $\mathrm{TNF} \alpha$ and increased the anti-atherogenic cytokine IL10. Although testosterone treatment of men with type 2 diabetes did not result in any significant immunomodulatory effect, the baseline levels of both IL6 and CRP, but not $\mathrm{TNF} \alpha$, were significantly inversely correlated with total and bioavailable amounts of circulating testosterone confirming that low testosterone is associated with inflammation [Kapoor et al. 2007c].

No adverse effects on clotting have been identified. In a study of testosterone replacement in men with chronic stable angina there were no changes in tissue activity of either tissue plasminogen activator (tpa) or plasminogen activator inhibitor type 2 (PAI-1), or fibrinogen levels [Smith et al. 2005a].

None of these studies or others [FernandezBalsells et al. 2010; Haddad et al. 2007; Calof et al. 2005] have reported increases in adverse effects of testosterone replacement on cardiovascular endpoints apart from a recent study published in the New England Fournal of Medicine [Basaria et al. 2010]. This study was unusual and does not reflect common clinical practice. The study was designed to increase muscle strength in frail elderly men. Testosterone gel was administered at a dose which was twice the recommended starting dose in a group of elderly men with a high level of comorbidities including hypertension and diabetes. These men had an increased incidence attributed potentially to cardiovascular events including oedema and selfreported syncope. The study was not powered to assess this aspect and although the results are of interest, they clearly require further investigation especially as other studies have not reported such effects in men treated within guidelines of common clinical practice.

\section{Summary}

There is strong evidence that a low testosterone level and clinical hypogonadism have a high prevalence in men with metabolic syndrome and/or type 2 diabetes. Many components of metabolic syndrome are adversely affected especially in relation to cardiovascular risk in the presence of hypogonadism. Testosterone deficiency is a risk factor in itself for the subsequent development of the metabolic syndrome and type 2 diabetes.

Early interventional studies have shown that TRT in hypogonadal men with type 2 diabetes and/or metabolic syndrome has beneficial effects. These benefits have not only found that hypogonadal symptoms such as sexual function improve, but key metabolic markers also improve. It is important to recognize that these include central adiposity, insulin resistance and glycaemic control, all components of the metabolic syndrome and cardiovascular risk factors. No significant beneficial effects have been consistently identified on blood pressure, TGs or HDL-C. Furthermore testosterone replacement in several studies has been shown to have a small but significant effect in reducing cholesterol and LDL-C, also important cardiovascular risk factors. Taken into context that there is increasing evidence that low testosterone is associated with increased mortality, then it may be conceivable that physiological testosterone replacement potentially could enhance survival in these men. It is important that the diagnostic criteria for hypogonadism are confirmed before considering testosterone replacement according to international criteria [Bhasin et al. 2010; Wang et al. 2008]. We do not however know whether low testosterone is just a biomarker of the degree of illness or a contributory factor to the progression of atherosclerosis. Accumulating evidence now suggests that testosterone deficiency is a risk factor for cardiovascular disease and intervention may ameliorate the process. Active systemic inflammatory disorders including chronic infections may accelerate atherosclerotic progression and destabilize plaques. 
There is a clear need for a longer-term interventional study, ideally of 5-year duration, to examine the effect of testosterone on cardiovascular disease in men with metabolic syndrome and/or type 2 diabetes. The increasing evidence as reviewed here is becoming too strong to be ignored. It must also not be forgotten that TRT in hypogonadal men with or without metabolic syndrome or diabetes can have a major impact on the patient's quality of life and well-being.

\section{Funding}

This article received no specific grant from any funding agency in the public, commercial, or not-for-profit sectors.

\section{Conflict of interest statement}

Hugh Jones is Consultant for Prostrakan, Educational lectures and advisory boards for Bayer-Schering Pharma, Ferring and Prostrakan and Research grant from Bayer Schering Pharma.

\section{References}

Agarwal, P.K. and Oefelein, M.G. (2005) Testosterone replacement therapy after primary treatment for prostate cancer. F Urol 173: 533-536.

Agledahl, I., Hansen, J.B. and Svartberg, J. (2008) Impact of testosterone treatment on postprandial triglyceride metabolism in elderly men with subnormal testosterone levels. Scand F Clin Lab Investig 68: 641-648.

Alberti, K.G.M.M., Eckel, R.H., Grundy, S.M., Zimmet, P.Z., Cleeman, J.I., Donato, K.A. et al. (2009) Harmonizing the metabolic syndrome: a joint interim statement of the International Diabetes Federation Task Force on Epidemiology and Prevention; National Heart, Lung, and Blood Institute; American Heart Association; World Heart Federation; International Atherosclerosis Society; and International Association for the Study of Obesity. Circulation 120: 1640-1645.

Alexandersen, P., Haarbo, J., Byrjalsen, I., Lawaetz, H. and Christiansen, C. (1999) Natural androgens inhibit male atherosclerosis - a study in castrated, cholesterolfed rabbits. Circulat Res 84: 813-819.

Anderson, F.H., Francis, R.M. and Faulkner, K. (1996) Androgen supplementation in eugonadal men with osteoporosis - effects of 6 months of treatment on bone mineral density and cardiovascular risk factors. Bone 18: 171-177.

Araujo, A.B., Kupelian, V., Page, S.T., Handelsman, D.J., Bremner, W.J. and McKinlay, J.B. (2007)

Sex steroids and all-cause and cause-specific mortality in men. Arch Intern Med 167: 1252-1260.

Bagatell, C.J., Heiman, J.R., Matsumoto, A.M., Rivier, J.E. and Bremner, W.J. (1994) Metabolic and behavioral-effects of high-dose, exogenous testosterone in healthy-men. $\mathcal{F}$ Clin Endocrinol Metab 79: $561-567$.

Barrettconnor, E. (1992) Lower endogenous androgen levels and dyslipidemia in men with noninsulin-dependent diabetes-mellitus. Ann Intern Med 117: 807-811.

Basaria, S., Coviello, A.D., Travison, T.G., Storer, T.W., Farwell, W.R., Jette, A.M. et al. (2010) Adverse events associated with testosterone administration. N Engl f Med 363: 109-122.

Bhasin, S., Cunningham, G.R., Hayes, F.J., Matsumoto, A.M., Snyder, P.J., Swerdloff, R.S. et al. (2010) Testosterone therapy in men with androgen deficiency syndromes: an Endocrine Society Clinical Practice Guideline. $f$ Clin Endocrinol Metab 95: 2536-2559.

Blouin, K., Despres, J.P., Couillard, C., Tremblay, A., Prud'homme, D., Bouchard, C. et al. (2005)

Contribution of age and declining androgen levels to features of the metabolic syndrome in men. Metab Clin Exp 54: 1034-1040.

Bocchi, E.A., Carvalho, V.O. and Guimaraes, G.V. (2008) Inverse correlation between testosterone and ventricle ejection fraction, hemodynamics and exercise capacity in heart failure patients with erectile dysfunction. Int Braz f Urol 34: 302-310; discussion 310-302.

Bojesen, A., Juul, S., Birkebaek, N.H. and Gravholt, C.H. (2006) Morbidity in Klinefelter syndrome: a Danish register study based on hospital discharge diagnoses. F Clin Endocrinol Metab 91: 1254-1260.

Boyanov, M.A., Boneva, Z. and Christov, V.G. (2003) Testosterone supplementation in men with type

2 diabetes, visceral obesity and partial androgen deficiency. Aging Male 6: 1-7.

Calof, O.M., Singh, A.B., Lee, M.L., Kenny, A.M., Urban, R.J., Tenover, J.L. et al. (2005) Adverse events associated with testosterone replacement in middleaged and older men: a meta-analysis of randomized, placebo-controlled trials. F Gerontol Ser A-Biol Sci Med Sci 60(11): 1451-1457.

Chubb, S.A.P., Hyde, Z., Almeida, O.P., Flicker, L., Norman, P.E., Jamrozik, K. et al. (2008) Lower sex hormone-binding globulin is more strongly associated with metabolic syndrome than lower total testosterone in older men: the Health in Men Study. Eur $\mathcal{F}$ Endocrinol 158: 785-792.

Cohen, P.G. (1999) The hypogonadal-obesity cycle: role of aromatase in modulating the testosterone-estradiol shunt-a major factor in the genesis of morbid obesity. Med Hypoth 52: $49-51$.

Cohen, P.G. (2001) Aromatase, adiposity, aging and disease. The hypogonadal metabolic-atherogenicdisease and aging connection. Med Hypoth 56: $702-708$. 
Cohen, P.G. (2008) The hypoandrogenic-anabolic deficiency state: Endocrine and metabolic shifts in men. Med Hypoth 71: 805-807.

Corona, G., Mannucci, E., Forti, G. and Maggi, M. (2009) Hypogonadism, ED, metabolic syndrome and obesity: A pathological link supporting cardiovascular diseases. Int $\mathcal{F}$ Androl 32: 587-598.

Corona, G., Mannucci, E., Schulman, C., Petrone, L., Mansani, R., Cilotti, A. et al. (2006) Psychobiologic correlates of the metabolic syndrome and associated sexual dysfunction. Eur Urol 50: 595-604.

Corrales, J.J., Almeida, M., Burgo, R., Mories, M.T., Miralles, J.M. and Orfao, A. (2006) Androgenreplacement therapy depresses the ex vivo production of inflammatory cytokines by circulating antigenpresenting cells in aging type- 2 diabetic men with partial androgen deficiency. $\mathcal{F}$ Endocrinol 189: 595-604.

D’Agostino, P., Milano, S., Barbera, C., Di Bella, G., La Rosa, M., Ferlazzo, V. et al. (1999) Sex hormones modulate inflammatory mediators produced by macrophages, In: Cutolo, M., Masi, A.T., Bijlsma, J.W.J., Chikanza, I.C., Bradlow, H.L. and Castagnetta, L. (eds). Neuroendocrine Immune Basis of the Rheumatic Diseases, Vol. 876, New York Academy of Sciences: New York, pp. 426-429.

De Pergola, G. (2000) The adipose tissue metabolism: role of testosterone and dehydroepiandrosterone. Int $\mathcal{F}$ Obesity 24: S59-S63.

Demirbag, R., Yilmaz, R., Ulucay, A. and Unlu, D. (2005) The inverse relationship between thoracic aortic intima media thickness and testosterone level. Endocrine Res 31: 335-344.

Derweesh, I.H., DiBlasio, C.J., Kincade, M.C., Malcolm, J.B., Lamar, K.D., Patterson, A.L. et al. (2007) Risk of new-onset diabetes mellitus and worsening glycaemic variables for established diabetes in men undergoing androgen-deprivation therapy for prostate cancer. BfU Int

100: 1060-1065.

Dhindsa, S., Prabhakar, S., Sethi, M., Bandyopadhyay, A., Chaudhuri, A. and Dandona, P. (2004) Frequent occurrence of hypogonadotropic hypogonadism in type 2 diabetes. $\mathcal{F}$ Clin Endocrinol Metab 89: 5462-5468.

Diaz-Arjonilla, M., Schwarcz, M., Swerdloff, R.S. and Wang, C. (2009) Obesity, low testosterone levels and erectile dysfunction. Int $\mathcal{F}$ Impotence Res 21: 89-98.

Ding, E.L., Song, Y., Malik, V.S. and Liu, S. (2006) Sex differences of endogenous sex hormones and risk of type 2 diabetes: a systematic review and meta-analysis. FAMA 295: 1288-1299.

Fan, A.Z. and Dwyer, J.H. (2007) Sex differences in the relation of HDL cholesterol to progression of carotid intima-media thickness: the Los Angeles Atherosclerosis Study. Atherosclerosis 195: e191-e196.
Fernandez-Balsells, M.M., Murad, M.H., Lane, M., Lampropulos, J.F., Albuquerque, F., Mullan, R.J. et al. (2010) Adverse effects of testosterone therapy in adult men: a systematic review and meta-analysis. $\mathcal{F}$ Clin Endocrin Metab 95(6): 2560-2575.

Fukui, M., Kitagawa, Y., Nakamura, N., Kadono, M., Mogami, S., Hirata, C. et al. (2003) Association between serum testosterone concentration and carotid atherosclerosis in men with type 2 diabetes. Diabetes Care 26: 1869-1873.

Gapstur, S.M., Gann, P.H., Kopp, P., Colangelo, L., Longcope, C. and Liu, K. (2002) Serum androgen concentrations in young men: A longitudinal analysis of associations with age, obesity, and race. The CARDIA Male Hormone Study. Cancer Epidemiol Biomarkers Prevention 11: 1041-1047.

Garaulet, M., Perez-Llamas, F., Fuente, T., Zamora, S. and Tebar, F.J. (2000) Anthropometric, computed tomography and fat cell data in an obese population: relationship with insulin, leptin, tumor factor-alpha, sex hormone-binding globulin and sex hormones. Eur f Endocrinol 143: 657-666.

Gornstein, R.A., Lapp, C.A., Bustos-Valdes, S.M. and Zamorano, P. (1999) Androgens modulate interleukin- 6 production by gingival fibroblasts in vitro. F Periodontol 70: 604-609.

Grossmann, M., Gianatti, E.J. and Zajac, J.D. (2010) Testosterone and type 2 diabetes. Curr Opin Endocrinol Diabetes Obesity 17: 247-256.

Haddad, R.M., Kennedy, C.C., Caples, S.M., Tracz, M.J., Bolona, E.R., Sideras, K. et al. (2007) Testosterone and cardiovascular risk in men: a systematic review and meta-analysis of randomized placebo-controlled trials. Mayo Clin Proc 82(1): 29-39.

Haffner, S.M., Karhapaa, P., Mykkanen, L. and Laakso, M. (1994) Insulin-resistance, body-fat distribution, and sex-hormones in men. Diabetes 43: 212-219.

Haffner, S.M., Shaten, J., Stern, M.P., Smith, G.D. and Kuller, L. (1996) Low levels of sex hormonebinding globulin and testosterone predict the development of non-insulin-dependent diabetes mellitus in men. Am f Epidemiol 143: 889-897.

Haffner, S.M., Valdez, R.A., Stern, M.P. and Katz, M.S. (1993) Obesity, body-fat distribution and sexhormones in men. Int $\mathcal{F}$ Obesity 17: 643-649.

Hak, A.E., Witteman, J.C.M., de Jong, F.H., Geerlings, M.I., Hofman, A. and Pols, H.A.P. (2002) Low levels of endogenous androgens increase the risk of atherosclerosis in elderly men: The Rotterdam study. $\mathcal{F}$ Clin Endocrinol Metab 87: 3632-3639.

Hanefeld, M., Koehler, C., Gallo, S., Benke, I. and Ott, P. (2007) Impact of the individual components of the metabolic syndrome and their different combinations on the prevalence of atherosclerotic vascular 
disease in type 2 diabetes: the Diabetes in Germany (DIG) study. Cardiovasc Diabetol 6: 13.

Haring, R., Volzke, H., Steveling, A., Krebs, A., Felix, S.B., Schofl, C. et al. (2010) Low serum testosterone levels are associated with increased risk of mortality in a population-based cohort of men aged 20-79. Eur Heart F 31(12): 1494-1501.

Hatakeyama, H., Nishizawa, M., Nakagawa, A., Nakano, S., Kigoshi, T. and Uchida, K. (2002) Testosterone inhibits tumor necrosis factor-alphainduced vascular cell adhesion molecule-1 expression in human aortic endothelial cells. FEBS Lett 530: 129-132.

Hayes, F.J., Decruz, S., Seminara, S.B., Boepple, P.A. and Crowley, W.F. (2001) Differential regulation of gonadotropin secretion by testosterone in the human male: Absence of a negative feedback effect of testosterone on follicle-stimulating hormone secretion. f Clin Endocrinol Metab 86: 53-58.

Hayes, F.J., Seminara, S.B., Decruz, S., Boepple, P.A. and Crowley, W.F. (2000) Aromatase inhibition in the human male reveals a hypothalamic site of estrogen feedback. 7 Clin Endocrinol Metab 85: 3027-3035.

Heufelder, A.E., Saad, F., Bunck, M.C. and Gooren, L. (2009) Fifty-two-week treatment with diet and exercise plus transdermal testosterone reverses the metabolic syndrome and improves glycemic control in men with newly diagnosed type 2 diabetes and subnormal plasma testosterone. f Androl 30: 726-733.

Hill, S., Arutchelvam, V. and Quinton, R. (2009) Enclomiphene, an estrogen receptor antagonist for the treatment of testosterone deficiency in men. IDrugs 12: 109-119.

Hofbauer, L.C., Ten, R.M. and Khosla, S. (1999) The anti-androgen hydroxyflutamide and androgens inhibit interleukin- 6 production by an androgen-responsive human osteoblastic cell line. $\mathcal{F}$ Bone Mineral Res 14: 1330-1337.

Johannsson, G., Gibney, J., Wolthers, T., Leung, K.C. and Ho, K.K.Y. (2005) Independent and combined effects of testosterone and growth hormone on extracellular water in hypopituitary men. $\mathcal{F}$ Clin Endocrinol Metab 90: 3989-3994.

Johnsen, S.H., Mathiesen, E.B., Fosse, E., Joakimsen, O., Stensland-Bugge, E., Njolstad, I. et al. (2005)

Elevated high-density lipoprotein cholesterol levels are protective against plaque progression - a follow-up study of 1952 persons with carotid atherosclerosis - The Tromso study. Circulation 112: 498-504.

Jones, H., Howell, J. and Channer, K. (2010) Testosterone improves glycaemic control, insulin resistance, body fat and sexual function in men with the metabolic syndrome and/or type 2 diabetes: a Multicentre European Clinical Trial: the TIMES2 Study. Endocrine Abstracts 21: OC1.6.
Jones, T.H. (2007) Testosterone associations with erectile dysfunction, diabetes, and the metabolic syndrome. Eur Urol Suppl 6: 847-857.

Jones, T.H. (2010) Testosterone deficiency: a risk factor for cardiovascular disease? Trends Endocrinol Metab 21: 496-503.

Jones, T.H. and Saad, F. (2009) The effects of testosterone on risk factors for, and the mediators of, the atherosclerotic process. Atherosclerosis 207: 318-327.

Kapoor, D., Aldred, H., Clark, S., Channer, K.S. and Jones, T.H. (2007a) Clinical and biochemical assessment of hypogonadism in men with type 2 diabetes: correlations with bioavailable testosterone and visceral adiposity. Diabetes Care 30: 911-917.

Kapoor, D., Clarke, S., Channer, K.S. and Jones, T.H. (2007b) Erectile dysfunction is associated with low bioactive testosterone levels and visceral adiposity in men with type 2 diabetes. Int $\mathcal{F}$ Androl 30: 500-507.

Kapoor, D., Clarke, S., Stanworth, R., Channer, K.S. and Jones, T.H. (2007c) The effect of testosterone replacement therapy on adipocytokines and C-reactive protein in hypogonadal men with type 2 diabetes. Eur $\mathcal{F}$ Endocrinol 156: 595-602.

Kapoor, D., Goodwin, E., Channer, K.S. and Jones, T.H. (2006) Testosterone replacement therapy improves insulin resistance, glycaemic control, visceral adiposity and hypercholesterolaemia in hypogonadal men with type 2 diabetes. Eur $\mathcal{F}$ Endocrinol 154: 899-906.

Kapoor, D., Malkin, C.J., Channer, K.S. and Jones, T.H. (2005) Androgens, insulin resistance and vascular disease in men. Clin Endocrinol (Oxf) 63: 239-250.

Keating, N.L., O’Malley, A.J. and Smith, M.R. (2006) Diabetes and cardiovascular disease during androgen deprivation therapy for prostate cancer. 7 Clin Oncol 24: 4448-4456.

Kenny, A.M., Gruman, C.A., Fabregas, G., Biskup, B. and Mansoor, G. (2001) Effects of testosterone on lipids and vascular reactivity in older men. Gerontologist 41: 185-185.

Khaw, K.-T., Dowsett, M., Folkerd, E., Bingham, S., Wareham, N., Luben, R. et al. (2007) Endogenous testosterone and mortality due to all causes, cardiovascular disease, and cancer in men: European Prospective Investigation Into Cancer in Norfolk (EPIC-Norfolk) Prospective Population Study. Circulation 116: 2694-2701.

Khaw, K.T. and Barrett-Connor, E. (1992) Lower endogenous androgens predict central adiposity in men. Ann Epidemiol 2: 675-682.

Khaw, K.T. and Barrettconnor, E. (1988)

Blood-pressure and endogenous testosterone in men-an inverse relationship. $\mathcal{F}$ Hypertension 6: $329-332$

Kupelian, V., Page, S.T., Araujo, A.B., Travison, T.G., Bremner, W.J. and McKinlay, J.B. (2006) Low sex hormone-binding globulin, total testosterone, 
and symptomatic androgen deficiency are associated with development of the metabolic syndrome in nonobese men. $\mathcal{F}$ Clin Endocrinol Metab 91: 843-850.

Kylin, E. (1923) Studien über das HypertonieHyperglykämie-Hyperurikämiesyndrom. Zentrabl $f$ innere Med Leipz 181: 105-127.

Laaksonen, D.E., Niskanen, L., Punnonen, K., Nyyssonen, K., Tuomainen, T.P., Salonen, R. et al. (2003) Sex hormones, inflammation and the metabolic syndrome: a population-based study. Eur $\mathcal{F}$ Endocrinol 149: 601-608.

Laaksonen, D.E., Niskanen, L., Punnonen, K., Nyyssonen, K., Tuomainen, T.P., Valkonen, V.P. et al. (2005) The metabolic syndrome and smoking in relation to hypogonadism in middle-aged men: a prospective cohort study. $\mathcal{F}$ Clin Endocrinol Metab 90: 712-719.

Laaksonen, D.E., Niskanen, L., Punnonen, K., Nyyssonen, K., Tuomainen, T.P., Valkonen, V.P. et al. (2004) Testosterone and sex hormone-binding globulin predict the metabolic syndrome and diabetes in middle-aged men. Diabetes Care 27: 1036-1041.

Lanfranco, F., Zitzmann, M., Simoni, M. and Nieschlag, E. (2004) Serum adiponectin levels in hypogonadal males: influence of testosterone replacement therapy. Clin Endocrinol 60: 500-507.

Laughlin, G.A., Barrett-Connor, E. and Bergstrom, J. (2008) Low serum testosterone and mortality in older men. F Clin Endocrinol Metab 93: 68-75.

Li, Z.G., Danis, V.A. and Brooks, P.M. (1993) Effect of gonadal-steroids on the production of IL-1 and IL-6 by blood mononuclear-cells invitro. Clin Exp Rheumatol 11: 157-162.

Liva, S.M. and Voskuhl, R.R. (2001) Testosterone acts directly on CD4(+) T lymphocytes to increase IL-10 production. F Immunol 167: 2060-2067.

Makhsida, N., Shah, J., Yan, G., Fisch, H. and Shabsigh, R. (2005) Hypogonadism and metabolic syndrome: Implications for testosterone therapy. F Urol 174: 827-834.

Malkin, C.J., Pugh, P.J., Morris, P.D., Asif, S., Jones, T.H. and Channer, K.S. (2010) Low serum testosterone and increased mortality in men with coronary heart disease. Heart, http://heart.bmj.com/content/ early/2010/09/28/hrt.2010.195412.abstract. Published Online First 19 October 2010.

Malkin, C.J., Pugh, P.J., Jones, R.D., Kapoor, D., Channer, K.S. and Jones, T.H. (2004a) The effect of testosterone replacement on endogenous inflammatory cytokines and lipid profiles in hypogonadal men. $\mathcal{F}$ Clin Endocrinol Metab 89: 3313-3318.

Malkin, C.J., Pugh, P.J., Morris, P.D., Kerry, K.E., Jones, R.D., Jones, T.H. et al. (2004b) Testosterone replacement in hypogonadal men with angina improves ischaemic threshold and quality of life. Heart 90: 871-876.

Maravelias, C., Dona, A., Stefanidou, M. and Spiliopoulou, C. (2005) Adverse effects of anabolic steroids in athletes-a constant threat. Toxicol Lett 158: $167-175$.

Marin, P., Holmang, S., Gustafsson, C., Jonsson, L., Kvist, H., Elander, A. et al. (1993) Androgen treatment of abdominally obese men. Obes Res 1: 245-251.

Marin, P., Oden, B. and Bjorntorp, P. (1995)

Assimilation and mobilization of triglycerides in subcutaneous abdominal and femoral adipose-tissue in-vivo in men-effects of androgens. $\mathcal{F}$ Clin Endocrinol Metab 80: 239-243.

Maron, D.J. (2000) The epidemiology of low levels of high-density lipoproteins cholesterol in patients with and without coronary artery disease. Am $\mathcal{F}$ Cardiol 86(12A): $11 \mathrm{~L}-14 \mathrm{~L}$.

Messerli, F.H., Garavaglia, G.E., Schmieder, R.E., Sundgaardriise, K., Nunez, B.D. and Amodeo, C. (1987) Disparate cardiovascular findings in men and women with essential-hypertension. Ann Intern Med 107: 158-161.

Mottram, D.R. and George, A.J. (2000) Anabolic steroids. Best Pract Res Clin Endocrinol Metab 14: 55-69.

Muller, M., van den Beld, A.W., Bots, M.L., Grobbee, D.E., Lamberts, S.W. and van der Schouw, Y.T. (2004) Endogenous sex hormones and progression of carotid atherosclerosis in elderly men. Circulation 109: 2074-2079.

Muraleedharan, V., Ranjan, N., Rolfe, C. and Jones, T.H. (2010) The effect of testosterone undecanoate on cardiovascular risk factors in men with hypogonadism in clinical practice. Endocrine Abstracts 31(3 Suppl.1): S464.

Nettleship, J.E., Jones, T.H., Channer, K.S. and Jones, R.D. (2007a) Physiological testosterone replacement therapy attenuates fatty streak formation and improves high-density lipoprotein cholesterol in the Tfm mouse: An effect that is independent of the classic androgen receptor. Circulation 116: 2427-2434.

Nettleship, J.E., Pugh, P.J., Channer, K.S., Jones, T. and Jones, R.D. (2007b) Inverse Relationship between Serum Levels of Interleukin-1? and Testosterone in Men with Stable Coronary Artery Disease. Hormone Metab Res 39: 366-371.

Oh, J.Y., Barrett-Connor, E., Wedick, N.M. and Wingard, D.L. (2002) Endogenous sex hormones and the development of type 2 diabetes in older men and women: the Rancho Bernardo Study. Diabetes Care 25: $55-60$.

Olufadi, R. and Byrne, C.D. (2008) Clinical and laboratory diagnosis of the metabolic syndrome. $f$ Clin Pathol 61: 697-706.

Pasquali, R., Casimirri, F., Balestra, V., Flamia, R., Melchionda, N., Fabbri, R. et al. (1991) The relative 
contribution of androgens and insulin in determining abdominal body-fat distribution in premenopausal women. F Endocrinol Invest 14: 839-846.

Pitteloud, N., Mootha, V.K., Dwyer, A.A., Hardin, M., Lee, H., Eriksson, K.F. et al. (2005) Relationship between testosterone levels, insulin sensitivity, and mitochondrial function in men. Diabetes Care 28: 1636-1642.

Reaven, G.M. (1988) Role of insulin resistance in human-disease. Diabetes 37: 1595-1607.

Rebuffescrive, M., Marin, P. and Bjorntorp, P. (1991) Effect of testosterone on abdominal adipose-tissue in men. Int $\mathcal{F}$ Obesity 15: 791-795.

Reckelhoff, J.F., Yanes, L.L., Iliescu, R., Fortepiani, L.A. and Granger, J.P. (2005) Testosterone supplementation in aging men and women: possible impact on cardiovascular-renal disease. Am $\mathcal{F}$ Physiol Renal Physiol 289: F941-F948.

Reckelhoff, J.F., Zhang, H.M. and Granger, J.P. (1998) Androgen receptor antagonism attenuates the progression of hypertension in male spontaneously hypertensive rats. Hypertension 32: 69.

Rodriguez, A., Muller, D.C., Metter, E.J., Maggio, M., Harman, S.M., Blackman, M.R. et al. (2007) Aging, androgens, and the metabolic syndrome in a longitudinal study of aging. 7 Clin Endocrinol Metab 92: 3568-3572.

Saad, F., Gooren, L., Haider, A. and Yassin, A. (2007) An exploratory study of the effects of 12 month administration of the novel long-acting testosterone undecanoate on measures of sexual function and the metabolic syndrome. Arch Androl 53: 353-357.

Saad, F., Gooren, L.J., Haider, A. and Yassin, A. (2008) A dose-response study of testosterone on sexual dysfunction and features of the metabolic syndrome using testosterone gel and parenteral testosterone undecanoate. F Androl 29: 102-105.

Seidell, J.C., Bjorntorp, P., Sjostrom, L., Kvist, H. and Sannerstedt, R. (1990) Visceral fat accumulation in men is positively associated with insulin, glucose, and c-peptide levels, but negatively with testosterone levels. Metab Clin Exp 39: 897-901.

Selvin, E., Nelson, W.G., Feinleib, M., Dobs, A., Zhang, L., Basaria, S. et al. (2007) Androgens and diabetes in men-Results from the Third National Health and Nutrition Examination Survey

(NHANES III). Diabetes Care 30: 234-238.

Shabsigh, R., Arver, S., Channer, K.S., Eardley, I., Fabbri, A., Gooren, L. et al. (2008) The triad of erectile dysfunction, hypogonadism and the metabolic syndrome. Int $\mathcal{F}$ Clin Pract 62: 791-798.

Shores, M.M., Matsumoto, A.M., Sloan, K.L. and Kivlahan, D.R. (2006) Low serum testosterone and mortality in male veterans. Arch Intern Med 166: 1660-1665.

Simon, D., Charles, M.A., Nahoul, K., Orssaud, G., Kremski, J., Hully, V. et al. (1997) Association between plasma total testosterone and cardiovascular risk factors in healthy adult men: The Telecom Study. $\mathcal{F}$ Clin Endocrinol Metab 82: 682-685.

Simon, D., Preziosi, P., Barrettconnor, E., Roger, M., Saintpaul, M., Nahoul, K. et al. (1992) Interrelation between plasma testosterone and plasma-insulin in healthy adult men-the Telecom study. Diabetologia 35: 173-177.

Simons, L.A., McCallum, J., Friedlander, Y. and Simons, J. (1998) Risk factors for ischemic stroke-Dubbo Study of the elderly. Stroke 29: 1341-1346.

Singh, R., Artaza, J.N., Taylor, W.E., GonzalezCadavid, N.F. and Bhasin, S. (2003) Androgens stimulate myogenic differentiation and inhibit adipogenesis in $\mathrm{C} 3 \mathrm{H} 10 \mathrm{~T} 1 / 2$ pluripotent cells through an androgen receptor-mediated pathway. Endocrinology 144: 5081-5088

Smith, A.M., English, K.M., Malkin, C.J., Jones, R.D., Jones, T.H. and Channer, K.S. (2005a)

Testosterone does not adversely affect fibrinogen or tissue plasminogen activator (tPA) and plasminogen activator inhibitor-1 (PAI-1) levels in 46 men with chronic stable angina. Eur F Endocrinol 152: 285-291.

Smith, G.D., Ben-Shlomo, Y., Beswick, A., Yarnell, J., Lightman, S. and Elwood, P. (2005b) Cortisol, testosterone, and coronary heart disease: prospective evidence from the Caerphilly Study. Circulation 112: 332-340.

Smith, J.C., Bennett, S., Evans, L.M., Kynaston, H.G., Parmar, M., Mason, M.D. et al. (2001) The effects of induced hypogonadism on arterial stiffness, body composition, and metabolic parameters in males with prostate cancer. $\mathcal{F}$ Clin Endocrinol Metab 86: 4261-4267.

Stanworth, R., Kapoor, D., Channer, K. and Jones, T. (2008) Androgen receptor CAG repeat polymorphism is associated with serum testosterone levels, obesity and serum leptin in men with type 2 diabetes. Eur $\mathcal{F}$ Endocrinol EJE-08-0266.

Stanworth, R.D. and Jones, T.H. (2009)

Testosterone in obesity, metabolic syndrome and type 2 diabetes. Adv Managem Testosterone Deficiency 37: 74-90.

Stanworth, R.D., Kapoor, D., Channer, K.S. and Jones, T.H. (2007) Testosterone levels correlate positively with HDL cholesterol levels in men with type 2 diabetes. Endocrine Abstracts 14: P628.

Stellato, R.K., Feldman, H.A., Hamdy, O., Horton, E.S. and McKinlay, J.B. (2000) Testosterone, sex hormone-binding globulin, and the development of type 2 diabetes in middle-aged men-Prospective results from the Massachusetts Male Aging Study. Diabetes Care 23: 490-494.

Sullivan, M.L., Martinez, C.M., Gennis, P. and Gallagher, E.J. (1998) The cardiac toxicity of anabolic steroids. Prog Cardiovasc Dis 41: 1-15. 
Svartberg, J., Von Muhlen, D., Mathiesen, E., Joakimsen, O., Bonaa, K.H. and Stensland-Bugge, E. (2006) Low testosterone levels are associated with carotid atherosclerosis in men. $\mathcal{F}$ Intern Med 259: 576-582.

Svartberg, J., von Muhlen, D., Schirmer, H., BarrettConnor, E., Sundfjord, J. and Jorde, R. (2004) Association of endogenous testosterone with blood pressure and left ventricular mass in men. The Tromso Study. Eur F Endocrinol 150: 65-71.

Tivesten, Ã., Vandenput, L., Labrie, F., Karlsson, M.K., Ljunggren, Ã., Mellström, D. et al. (2009) Low serum testosterone and estradiol predict mortality in elderly men. F Clin Endocr Metab 94(7): 2482-2488.

Thompson, P.D., Cullinane, E.M., Sady, S.P., Chenevert, C., Saritelli, A.L., Sady, M.A. et al. (1989) Contrasting effects of testosterone and stanozolol on serum lipoprotein levels. $\mathcal{F A M A}$ 261: 1165-1168.

Tomaszewski, M., Charchar, F.J., Maric, C., Kuzniewicz, R., Gola, M., Grzeszczak, W. et al. (2009) Association between lipid profile and circulating concentrations of estrogens in young men. Atherosclerosis 203: 257-262.

Traish, A.M., Guay, A., Feeley, R. and Saad, F. (2009) The dark side of testosterone deficiency: I. Metabolic syndrome and erectile dysfunction. $\mathcal{F}$ Androl 30: $10-22$.

Tsai, E.C., Boyko, E.J., Leonetti, D.L. and Fujimoto, W.Y. (2000) Low serum testosterone level as a predictor of increased visceral fat in Japanese-American men. Int $\mathcal{F}$ Obesity 24: 485-491.

Tsai, E.C., Fujimoto, W.Y., Matsumoto, A.M. and Boyko, E.J. (2004) Association of bioavailable, free, and total testosterone with insulin resistance-influence of sex hormone-binding globulin and body fat. Diabetes Care 27: 861-868.

Uyanik, B.S., Ari, Z., Gumus, B., Yigitoglu, R. and Arslan, T. (1997) Beneficial effects of testosterone undecanoate on the lipoprotein profiles in healthy elderly men - a placebo controlled study. Fapanese Heart f 38: 73-82.

Vikan, T., Schirmer, H., Njolstad, I. and Svartberg, J. (2009) Endogenous sex hormones and the prospective association with cardiovascular disease and mortality in men: the Tromso Study. Eur F Endocrinol 161(3): 435-442.

Vague, J. (1947) Sexual differentiation. A factor affecting the forms of obesity. Presse Med 30: 339-340.

Vaidya, D., Dobs, A., Gapstur, S.M., Golden, S.H., Hankinson, A., Liu, K. et al. (2008) The association of endogenous sex hormones with lipoprotein subtraction profile in the Multi-Ethnic Study of Atherosclerosis. Metab Clin Exp 57: 782-790.

Van Pottelbergh, I., Braeckman, L., De Bacquer, D., De Backer, G. and Kaufman, J.M. (2003) Differential contribution of testosterone and estradiol in the determination of cholesterol and lipoprotein profile in healthy middle-aged men. Atherosclerosis 166: 95-102.

Vermeulen, A., Goemaere, S. and Kaufman, J.M. (1999) Testosterone, body composition and aging. f Endocrinol Invest 22(5 Suppl): 110-116.

Vermeulen, A., Kaufman, J.M., Goemaere, S. and van Pottelberg, I. (2002) Estradiol in elderly men. Aging Male 5: 98-102.

Wang, C., Nieschlag, E., Swerdloff, R., Behre, H.M., Hellstrom, W.J., Gooren, I.J. et al. (2008)

Investigation, treatment and monitoring of late-onset hypogonadism in males. Eur $\mathcal{F}$ Endocrinol

159: 507-514.

Whitsel, E.A., Boyko, E.J., Matsumoto, A.M., Anawalt, B.D. and Siscovick, D.S. (2001)

Intramuscular testosterone esters and plasma lipids in hypogonadal men: A meta-analysis. $\mathrm{Am} \mathcal{F} \mathrm{Med}$ 111: 261-269.

WHO (2010) Global strategy on diet, physical activity and health - Obesity and Overweight. http:// www.who.int/dietphysicalactivity/publications/facts/ obesity/en/

Yanase, T., Fan, W., Kyoya, K., Min, L., Takayanagi, R., Kato, S. et al. (2008) Androgens and metabolic syndrome: Lessons from androgen receptor knock out (ARKO) mice. F Steroid Biochem Mol Biol 109: 254-257.

Yassin, A.A., Saad, F. and Gooren, L.J. (2008) Metabolic syndrome, testosterone deficiency and erectile dysfunction never come alone. Andrologia 40: 259-264.

Yasui, T., Uemura, H., Irahara, M., Arai, M., Kojimahara, N., Okabe, R. et al. (2008) Associations of endogenous sex hormones and sex hormone-binding globulin with lipid profiles in aged Japanese men and women. Clin Chim Acta 398: 43-47.

Yialamas, M.A., Dwyer, A.A., Hanley, E., Lee, H., Pitteloud, N. and Hayes, F.J. (2007) Acute sex steroid withdrawal reduces insulin sensitivity in healthy men with idiopathic hypogonadotropic hypogonadism. f Clin Endocrinol Metab 92: 4254-4259.

Yusuf, S., Hawken, S., Ounpuu, S., Dans, T., Avezum, A., Lanas, F. et al. (2004) Effect of potentially modifiable risk factors associated with myocardial infarction in 52 countries (the INTERHEART study): case-control study. Lancet 364: 937-952.

Zgliczynski, S., Ossowski, M., SlowinskaSrzednicka, J., Brzezinska, A., Zgliczynski, W., Soszynski, P. et al. (1996) Effect of testosterone replacement therapy on lipids and lipoproteins in hypogonadal and elderly men. Atherosclerosis 121: 35-43.

Zitzmann, M. (2009) Testosterone deficiency, insulin resistance and the metabolic syndrome. Nature Rev Endocrinol 5: 673-681.

Zitzmann, M., Brune, M., Kornmann, B., Gromoll, J., von Eckardstein, S., von Eckardstein, A. et al. (2001) 
The CAG repeat polymorphism in the AR gene affects high density lipoprotein cholesterol and arterial vasoreactivity. F Clin Endocrinol Metab 86: 4867-4873.

Zitzmann, M. and Nieschlag, E. (2003) The CAG repeat polymorphism within the androgen receptor gene and maleness. Int $\mathcal{F}$ Androl 26: 76-83.

Zitzmann, M. and Nieschlag, E. (2007) Androgen receptor gene CAG repeat length and body mass index modulate the safety of long-term intramuscular testosterone undecanoate therapy in hypogonadal men. 7 Clin Endocrinol Metab 92: 3844-3853.

Zumoff, B., Strain, G.W., Miller, L.K., Rosner, W., Senie, R., Seres, D.S. et al. (1990) Plasma-free and non-sex-hormone-binding-globulin-bound testosterone are decreased in obese men in proportion to their degree of obesity. 7 Clin Endocrinol Metab 71: 929-931.
Visit SAGE journals online http://tae.sagepub.com

(S)SAGEJOURNALS

Online 